\title{
El restablecimiento de relaciones diplomáticas entre Cuba y Estados Unidos desde un contexto radial
}

\author{
The diplomatic relationship between Cuba and USA in a radial \\ context
}

Tania Vazquez Luna tvluna@uclv.cu

http://orcid.org/0000-0001-6897-0669

Universidad Central Marta Abreu de Las Villas (Cuba)

\section{Resumen}

El 17 de diciembre de 2014, marcó el inicio del proceso de restablecimiento de relaciones diplomáticas entre Cuba y Estados Unidos. El protagonismo de los medios de comunicación cubanos en este escenario, ha sido fundamental, destacándose la radio por su inmediatez y capacidad expresiva en la actividad periodística. El objetivo de la investigación es caracterizar el discurso periódico de la emisora provincial $C M H W$ en torno al proceso de restablecimiento de relaciones diplomáticas entre Cuba y Estados Unidos durante el período 2015-2016.

Para ello la alternativa metodológica propuesta es cualitativa. Se empleó en la investigación, el estudio de caso. Las técnicas escogidas, fueron la observación no participante; la revisión de documentos; la entrevista en profundidad y el análisis del discurso. De manera general, el discurso periodístico de la emisora $C M H W$ sobre la temática del restablecimiento de relaciones entre Cuba y Estados Unidos se caracteriza por ser informativo, de carácter legitimador, de autodefensa y unificador. 
Palabras clave: Discurso periodístico; radio; emisora $C M H W$; restablecimiento de relaciones diplomáticas Cuba-Estados Unidos.

\section{Abstract}

On December $17^{\mathrm{TH}}, 2014$ marked the beginning of reestablishment diplomatic relate between Cuba and United States of American especially to the radio for its expressive capacity in journalists activities. The main objective research is to characterize the CMHW broadcasting journalist discourse to half close the establishment diplomatic relate between Cuba and United States of American during 2015-2016 period.

For that matter, the methodology alternative offer is the qualitative. Employed as research the study's case, the choose technique were the non-participant observation, the documents revision, the depth document interview and the discourse analysis. In generally the journalist discourse of $C M H W$ broadcasting about the reestablishment diplomatic relate between Cuba and United States of American is characterized for the legitimed, character in formation of selfdefense and unify.

Keywords: Journalist discourse; radio; CMHW broadcasting; reestablishment diplomatic relate Cuba-United States of American.

El 17 de diciembre de 2014, los presidentes de Estados Unidos y Cuba anunciaron públicamente la decisión de restablecer relaciones diplomáticas, quebrantadas oficialmente en 1961. Según Ricardo Domínguez Guadarrama: "La lógica indicaba que el proceso para restablecer y normalizar las relaciones bilaterales entre Estados Unidos y Cuba, debería terminar o mostrar avances considerables y de ser posible irreversibles para enero de 2017, cuando concluya el mandato de Obama" (2015: 5). El período comprendido entre los años 2015 y finales del 2016 se caracterizó por ser una etapa prolífera en función de la normalización de los vínculos.

En la coyuntura se desarrollaron disímiles acontecimientos que patentaron el avance paulatino de las relaciones. El papel de la prensa en general, ha sido fundamental en este contexto debido al impacto que ha tenido la declaración del restablecimiento de relaciones entre Cuba y Estados Unidos. "La cobertura informativa durante este año de negociaciones dejó la certeza 
de que nuestro sistema de comunicación debe acompañar las necesidades informativas de nuestro pueblo, pues en el mundo actual la arquitectura política está basada en la arquitectura mediática" (Unión de Periodistas de Cuba, 2017, párr. 4).

Catalogado como un hecho trascendente y complejo, el restablecimiento de relaciones diplomáticas entre los gobiernos de Cuba y Estados Unidos suscita aproximaciones y reflexiones profundas. Se trata de un proceso que conlleva variadas implicaciones no solo políticas y sociales, sino también comunicativas.

En las coyunturas del restablecimiento de relaciones entre Cuba y Estados Unidos, el quehacer de los medios de comunicación cubanos, constituye un importante campo de estudio, en la representación de una realidad tan compleja. Sobre todo la radio, un medio con marcadas potencialidades expresivas en el uso de elementos verbales y no verbales dentro de la actividad periodística. Este es un terreno poco explorado en los estudios de la radio nacional y de las emisoras provinciales. Ante esta carencia, se presenta la necesidad de comprender el discurso periodístico que, sobre la temática de restablecimiento de las relaciones entre Cuba y Estados Unidos, articula una emisora provincial como la CMHW.

En el sistema de radiodifusión cubano, las emisoras provinciales se presentan como principales exponentes del acontecer territorial y nacional. La CMHW es considerada una de las principales emisoras provinciales de la región central de Cuba, y es vanguardia en el radio periodismo a nivel nacional. Los medios provinciales, atendiendo al sistema de emisoras radiales establecido en Cuba, también encuentran su pertinencia dentro de un contexto ya definido como complejo, que requiere de análisis, debates y participación ciudadana a través de esas emisoras definidas como cercanas. La radio provincial se convierte en un importante exponente de la realidad local, siendo un medio de comunicación inmediato y próximo a su audiencia.

La relevancia de estudiar los elementos que mediaron la selección, construcción y divulgación del discurso periodístico de la CMHW en torno al contexto de restablecimiento de relaciones diplomáticas entre Cuba y Estados Unidos radica en las complejidades que entraña el proceso. El aporte de la investigación, es la representación de un escenario tan complicado y de tanta actualidad, desde la mirada de una emisora de radio provincial. El análisis permite describir el trabajo comunicativo de los emisores como un proceso mediado por disímiles elementos, a la vez que permite describir las prácticas comunicativas que dan lugar a los contenidos emitidos por la emisora y su alcance a nivel provincial.

Sirvieron de referentes investigaciones vinculadas a la actividad radial como la tesis en opción al grado de Doctor en Ciencias de la Comunicación de Ana Teresa Badía titulada: Bases 
teórico-metodológicas para el análisis del discurso radiofónico como fuente de reproducción ideológica. La Voz de América: un estudio de caso (2006-2009) de 2010 y estudios más recientes como "Ideología en The New York Times y El Nuevo Herald: análisis ideológico del discurso periodístico sobre el tema Relaciones Cuba-Estados Unidos" (2016) de Regla de la Caridad Abreu Gaínza. Sin embargo, no existen estudios vinculados directamente al discurso periodístico sobre una temática de tanta actualidad como el restablecimiento de relaciones entre Cuba y Estados Unidos desde la emisora provincial CMHW.

\section{Referentes teóricos}

Los medios de comunicación se inatauran como actores sociales que fungen como emisores en la cobertura de los hechos significativos o de actualidad, pero que en su desarrollo extrapolan las relaciones sociales. La vinculación de la ideología y el papel de las instituciones en el proceso de reproducción de la vida social en el plano espiritual, se convierte en referente indispensable para comprender la maquinaria de reproducción mediática. Los medios de comunicación se imbrican como instituciones que producen y reproducen ideologías que transfiguran las representaciones sociales a un nivel simbólico. La reproducción ideológica implica continuidad de las estructuras, las normas de todo un sistema social y en cuyos mecanismos reconoce a los medios de comunicación como articuladores de las relaciones sociales que le dan sentido a la estructura social (Badía, 2010).

Muchos autores proponen una reinterpretación de la ideología y su relación con los mass media. John B. Thompson (1999) enmarca sus estudios en el desarrollo de los medios de comunicación y su influencia en la vida de las sociedades modernas. Su ofrecimiento teórico concibe la ideología desde su proyección simbólica respondiendo a la sistematización de la producción y circulación a través de los medios de comunicación.

Teun Van Dijk postula que la ideología se presenta como: "Sistema de creencias o, dicho de otra forma, las creencias compartidas por los miembros de un grupo" (s.f., p. 30). Para él, la ideología se supone como el fundamento sobre el cual se articulan las representaciones sociales compartidas por un grupo social. Su propuesta no reduce el concepto de ideologías como una acción de dominación unidireccional de una clase sobre otra, sino como parte de un sistema de valores, ideas, concepciones que toman sentido en un grupo social, y que es compartido por sus miembros. 
Extrapolando la acepción al contexto cubano, la actividad ideológica se asume como un sistema de producción y reproducción de ideas y valores, difundidos de manera sistemática por múltiples vías con la finalidad de reproducir convicciones y actitudes revolucionarias que respondan a los intereses del proceso socialista cubano (Machado, 2006: 8).

Las instituciones encargadas de construir sentidos compartidos a nivel social (medios de comunicación, escuela, organizaciones políticas, entre otros) responden a la necesidad de defender los intereses de la Revolución cubana y a los intereses políticos de la clase obrera (Domínguez, Rego y Castilla, 2014). La ideología de la revolución cubana se expresa en los mensajes políticos, en la opinión pública, en los contenidos de los medios de comunicación, en la formación escolar y en la educación familiar, en todos los ámbitos de la sociedad. Los medios de comunicación en Cuba dirigen su trabajo ideológico al desarrollo de las tareas revolucionarias y constituye un referente de vital importancia en el proceso de formación de la conciencia socialista. La actividad comunicacional de los medios cubanos se manifiesta como un instrumento de promoción y defensa de la cultura, de la independencia y la soberanía nacional (Machado, 2016).

Igualmente el acceso a los espacios públicos se determina como un componentes que permite reforzar y legitimar la ideología. En la sociedad cubana, los medios de comunicación se rigen por una política de comunicación común dirigida, sobre todo, al sostenimiento de valores instituidos y reconocidos de reproducción ideológica del sistema político (Domínguez et al., 2014).

La comunicación juega un papel fundamental dentro de la legitimación del ejercicio político. Esta herramienta concebida por el hombre político para comunicar sus ideas acompaña el devenir histórico de la humanidad (Dell'Oro, 2013). La comunicación política ha sido de especial interés para los teóricos (Exeni, 2005; Mazzoleni, 2010; Wolton, 2010) quienes la definen como un proceso complejo.

Según refiere, María Canel (2006: 27), la comunicación política forma parte de la actividad de instituciones o personas en la que como resultado de la interacción que establecen, se produce un intercambio de mensajes con los que se articula la toma de decisiones políticas. La autora asume la relevancia de la actividad periodística en la construcción de la realidad y la legitimación social de la información.

Los medios ejercen el control social sobre el recurso del discurso público. El sostenimiento del sistema político opera sobre la reproducción ideológica en función de legitimar aquellas creencias, valores o percepciones. "Los medios no actúan como agentes neutrales de información, sino que toman un papel activo en el proceso politico, seleccionando y 
estructurando la información, interpretando y evaluando la cadena de eventos ocurridos" (Di Palma, 2014: 4).

En la actualidad, la comunicación política es expresión de recursos de comunicación, lenguajes tecnológicos, pautas de medios (Amado, 2013). La comunicación politica opera en la interseccion de tres actores fundamentales: partidos politicos, medios de comunicación y ciudadanos. En este espacio confluyen la interacción entre ellos y la generalización simbólica. Tenindo gran relevancia la ocnstruccion de los mensajes mediático como mediadores políticos (López, 2017).

En Cuba, la responsabilidad de responder eficientemente a la agenda pública es compartida por periodistas, comunicadores, realizadores, directivos de los medios, y también por el Estado y el Partido. De ahí el encargo de los medios de conciliar con las agendas públicas, su agenda y la agenda política (Machado, 2016). En la sociedad cubana los medios son un instrumento de unificación, orientación y educación en representación de los intereses del poder político de la clase obrera, la función del Partido y la Revolución (Domínguez et al., 2014).

Los discursos que circulan entre las estructuras o actores sociales, es medular en el sostenimiento del sistema político. En las últimas décadas la investigación en el campo de la comunicación política experimenta una renovación vinculada a la centralidad social adquirida por los medios de comunicación como mediador del entorno político y el proceso de formación de la opinión (Santillán, 2012).

Cada vez más la política se orienta a la mediatización por lo que es incuestionable que el discurso de la prensa mantiene una relación dinámica y dialéctica con el sistema político (Badía y Soler, 2015). El discurso periodístico, suscita cuestiones relativas a su demarcación como tipología referente a los mecanismos institucionales que lo presentan como instrumento de mediación social. Para Dolores Montero (1989) el discurso periodístico actúa como estructurador y ordenador de los contenidos aportados por el resto de discursos institucionales y sociales.

El discurso periodístico se presenta cargado de simbolismos, influencias e intenciones que van desde las estructuras de producción hasta los contextos de circulación. Los medios de comunicación incorporan a sus rutinas la reproducción de ideologías y estructuras sociales, lo que se manifiesta en su discurso. "En su carácter de actor social, cada medio dedicado a la cobertura de hechos de actualidad afectar el proceso de toma de decisiones en el sistema político con una tipología de discurso social (el discurso periodístico)" (Di Palma, 2014: 3).

Al referirse a los medios de comunicación es vital dirigir el análisis a la comunicación del mensaje. Pero aún más importante es la construcción del discurso periodístico, el cómo se 
cuenta, el proceso por el cual eso datos serán recopilados, ordenados y editados, en muchos casos, con fines subjetivos que responden a algo más que una simple labor periodística (López, 2017).

Los medios se convierten en una autoridad social que se fundamenta a través del discurso periodístico, que constituye un instrumento de definición de la realidad. Lo que permite a los medios estructurar, priorizar, enfocar y dirigir un discurso social que vincula a la gente con el mundo que le rodea y determina el papel de dominio en la esfera pública (Pérez, 2017).

Al referir las ideologías como parte estructural del discurso emergen estrategias a través de las cuales esta se articula al reforzar posiciones de autodefensa, legitimación y por ende de reproducción ideológica. El discurso periodístico devela un uso de estrategias que responden a una acción de reproducción ideológica y que se manifiestan como parte de su ordenamiento estructural. Tal hipótesis es defendida por teóricos como Van Dijk (2003) y John Thompson (1999) de quienes se apropia la investigación. Para ambos autores el análisis del discurso permite comprender la articulación de estructuras y estrategias. La base del análisis se corresponde con la organización de las formas, con sus atributos y relación estructural, ya que el discurso es el espacio donde confluyen procesos complejos de creación de sentidos y de reproducción ideológica.

Las investigaciones de newsmaking han dado cuenta de estos procedimientos de producción. Los estudios, entre los que se destaca la mirada del newsmaking, parten de la hipótesis general de que los productos informativos son una construcción organizacional que surge de su entorno y sus dinámicas (Retegui, 2017). La realidad se presenta mediatizada por los medios de comunicación quienes a partir de los fenómenos que ocurren y de la información construyen un discurso periodístico en el cual influyen otros factores (Parra y Domínguez, 2009).

Nora Gámez define las mediaciones como: "un proceso estructurante que resulta de la interrelación de los actores, agentes, procesos, y prácticas comunicativas con distintas instancias y procesos sociales" (2007: 208). El concepto se adecúa a la perspectiva de Pamela Shoemaker y Stephen Reese, quienes en La mediatización del mensaje: teoría de las influencias en el contenido de los medios de comunicación establecen niveles asociados a los factores internos y externos que incurren el contenido y la forma del discurso. Según estos autores los indicadores que intervienen en la producción de los mensajes responden a factores como las características individuales de los periodistas, las rutinas de trabajo, las pautas organizacionales del medio, las fuentes externas y la ideología social predominante.

El contexto físico igualmente imprime particularidades al proceso de construcción del discurso. Según Kaplún (2009) en todo medio de comunicación, el mensaje es afectado por las 
características del medio transmisor. El periodismo radiofónico igualmente imprime condicionantes dadas por la misma especificidad del medio. Los géneros periodísticos y los formatos que el medio pondere como parte de su producción periodística van a reflejar el interés por construir una realidad ya sea a través de la información, de la opinión o de la interpretación. La radio es un sistema colectivo de comunicación y expresión en el que los contenidos y las formas expresivas enriquecen, transforman los códigos y géneros en función del medio (Rodríguez, 2016).

Los teóricos establecen como elementos generales del lenguaje radial la voz humana, la música, el sonido y el silencio (Pafundi, 2015; Perona, 2006; Velázquez, 2011). La manera en que se combinen estos componentes del lenguaje radial, estructurarán de una forma u otra el producto final. Lo principal es tener en cuenta qué se quiere transmitir y en función de ello, determinar las emociones que se deseen despertar en la audiencia y el grado de complicidad que se desea compartir.

\section{Coordenadas metodológicas}

La alternativa metodológica designada fue la cualitativa debido al grado de interpretación que demanda la investigación. Cuestión medular para la caracterización del discurso periodístico, ya que la propuesta gravita en torno a la descripción de los factores que lo median y la identificación de elementos específicos en el trabajo periodístico.

El problema de investigación parte de qué características tiene el discurso periódico de la CMHW sobre el proceso de restablecimiento de relaciones diplomáticas entre Cuba y Estados Unidos en el período 2015-2016. El objetivo central del estudio es la caracterización del discurso periódico de la emisora $C M H W$ sobre la temática de restablecimiento de las relaciones diplomáticas entre Cuba y Estados Unidos.

Se asume el estudio de caso para sustentar la investigación. El estudio de caso es de tipo único o unidad de análisis, y de carácter descriptivo. Las técnicas de investigación propuestas son la observación no participante, la revisión de documentos y registros de audio, la entrevista en profundidad y el análisis del discurso. 


\section{Descripción operacional de categoría de análisis}

\section{Mediaciones}

-Individuales: creencias, actitudes, ética profesional, el sexo, la edad, entre otras.

-De rutinas: rutinas productivas, procedimientos, entre otras.

-Organizacionales: políticas del medio, estructura de la organización, roles, entre otras.

-Influencia extra medios: influencias del gobierno, partido político u otras instituciones externas al medio, fuentes empleadas, entre otras.

-Ideológicas: mecanismos simbólicos que dispone el medio y responden a la reproducción ideológica del sistema socialista cubano.

2. Estructuras y estrategias discursivas

\section{-Estructuras}

-Superestructura (titular, episodio, consecuencias, reacciones verbales, comentarios)

-Macro estructura semántica (tema global del texto, subtemas y valores noticia que se priorizan)

-Estructuras estilística

-Estructuras retóricas

-Estrategias

-Adjetivación

-Lexicalización negativas

-Estrategia de polarización

-La violación de las normas y los valores

-Modos en los que opera la ideología

3. Recursos radiofónicos

-Géneros y formatos del periodismo radial

-Cuñas radiales

-Música: funciones (gramatical, expresiva, descriptiva, reflexiva, ambiental)

-Sonido: funciones (ambiental-descriptivo, expresiva, narrativa, ornamental)

-Silencio

-Voz humana

En la investigación se empleó la muestra intencional, no probabilísticas. Dentro de la muestra se escogieron los trabajos periodísticos emitidos por la emisora durante el período 2015-2016. El muestreo se presentó por conveniencia ya que la recopilación del material fue grabada por el 
investigador en función de la disponibilidad de productos radiales. En total fueron 249 trabajos periodísticos emitidos por la emisora CMHW. Fue pertinente la selección de informantes claves conformando la muestra por siete informantes.

\section{Contexto de estudio}

La emisora CMHW fue fundada por el Dr. Ramón González el 15 de julio de 1933 en la provincia de Cienfuegos, Cuba. El señor Guillermo Domenech Galich fue el protagonista de la compra y traslado de la CMHW para la ciudad de Santa Clara con el apoyo de la firma cigarrera Trinidad y Hermano. Luego de múltiples modificaciones, la emisora es trasladada en 1971 a su ubicación actual: Parque Vidal Nro. 4 en Santa Clara, provincia Villa Clara, Cuba.

Durante los años de Revolución la emisora dio cobertura a los principales eventos acontecido en la provincia villaclareña. Ya convertida en emisora revolucionaria se produjeron transformaciones en concordancia con el nuevo contexto nacional. Se cambiaron programas, se formaron directivos y se sumaron artistas y escritores para renovar y fortalecer la programación radial.

En función de la misión de la emisora su accionar se dirige a informar, educar, instruir y recrear a la audiencia de Villa Clara, salvaguardando la política e ideología de la Revolución cubana. Los temas abordados fungen sobre la base de los intereses sociopolíticos, económicos y culturales de la población villaclareña. La labor de la CMHW prioriza el ámbito provincial y desde esa óptica asume el contexto nacional e internacional. Hecho que se evidenció el 17 de diciembre de 2014, con la cobertura de la declaración oficial de los presidentes de Estados Unidos y Cuba, Barack Obama y Raúl Castro, respectivamente.

Esa alocución fue transmitida por la emisora en cadera con la red de medios de comunicación cubanos. A partir del nuevo contexto político que vivía el país, la emisora se sumó al sistema nacional de comunicación con el objetivo de abordar el acontecer del proceso de normalización de relaciones diplomáticas entre ambas naciones. El primer vicepresidente de los Consejos de Estados y de Ministros de Cuba, Miguel Díaz-Canel en sus innumerables visitas a los principales medios de comunicación de la provincia de Villa Clara, reconocía la importancia de la CMHW como una de las principales emisoras de la región central del país y resaltaba la necesidad de mantener una cobertura constante de las actuales coyunturas, así como un flujo actualizado de información a la audiencia villaclareña. 


\title{
Análisis de los resultados
}

\section{De la radio, sus mediaciones}

El discurso periodístico de la $C M H W$ en torno a la temática de restablecimiento de relaciones diplomáticas entre Cuba y Estados Unidos, está mediado por varios factores. En la descripción de tales elementos irrumpió del contexto de estudio, la relevancia del elemento individual en la producción del discurso periodístico de la emisora provincial.

La importancia o la implicación que genera el tratamiento del tema desde un medio provincial son algunas de las posiciones personales que interceden en la forma y el contenido del discurso periodístico sobre la temática del restablecimiento de relaciones. La ética profesional y el grado de elaboración e investigación que exige de los periodistas al abordarlo, influye en los modos en que se articula el discurso de la emisora.

Según refieren los entrevistados:

\begin{abstract}
La temática internacional no es un tema fácil. Al contrario, es una temática compleja que exige preparación periodística y más en el tema de las relaciones Cuba-Estados Unidos. El periodista debe interiorizar, debe comprender para entonces emitir juicios, opiniones, valoraciones sobre lo que está aconteciendo en la actualidad. Este tema tiene que tener una preparación sólida (comunicación personal, 21 de marzo de 2017)
\end{abstract}

Las rutinas productivas que normaliza la emisora en su trabajo diario revelan la interrelación entre las propuestas que parten de los periodistas, y la agenda informativa de la emisora. En el proceso intervienen las incidencias que provienen del Instituto Cubano de Radio y Televisión (ICRT), como entidad rectora de la radiodifusión en Cuba.

El ICRT es nuestro órgano metodológico, nosotros nos guiamos por las políticas que traza el ICRT, la Dirección de Información y Propaganda de la Radio Cubana que nos traza unas líneas metodológicas en cuanto al plan temático mensual, el plan de trabajo por el cual nos guiamos. Es nuestra regla de trabajo y nosotros lo ajustamos a nuestro perfil, a nuestros públicos y a nuestras rutinas productivas (comunicación personal, 13 de mayo de 2017).

Las propuestas temáticas y metodológicas que intervienen en la producción periodística se manifiestan en la construcción del plan de coberturas informativas de la CMHW. "En la selección final de los temas intervienen la dirección del Informativo, el Partido y la dirección 
general de la emisora quienes finalmente determinan qué se va a cubrir, aunque los periodistas [reporteros] pueden proponer tema" (comunicación personal, 8 de febrero de 2017).

Al construir el plan de coberturas, no prevalece esta temática salvo una necesidad puntual del medio. La inclusión del tema en la programación informativa en la mayoría de los casos parte de la individualidad de reporteros o redactores.

La estructura organizativa del medio define los roles que ejecutarán los actores que intervienen en la producción periodística. Cuestión que se traduce en la supervisión, coordinación y toma de decisiones en torno a la articulación de un discurso coherente con los objetivos, normas y políticas dictados, tanto por el ICRT, como por la propia emisora CMHW. Las relaciones organizacionales median el discurso periodístico, a la hora de supervisar y disponer lo que saldrá al aire. Refieren los entrevistados que:

Juegan un papel supervisor, un papel digamos de velador, de que se maneje con los términos correctos y de que se haga cumplir los intereses que puedan tener tanto la dirección del país de manera más general y también territorial como el Partido o el gobierno de la provincia. A fin de cuentas, nos debemos a ellos (comunicación personal, 18 de abril de 2017).

La relación establecida entre la emisora y las instituciones externas emerge como un factor medular. Las fuentes de información como agentes externos al medio, se disponen como rutinarias en el trabajo periodístico. Las fuentes nacionales se priorizan en torno al tema de restablecimiento de relaciones diplomáticas entre Estados Unidos y Cuba, lo que intercede en la manifestación de un discurso muchas veces reproductivo.

Se trabaja el tema desde una posición que no genere contradicciones, reproduciendo las informaciones que vienen de los medios nacionales. Esto condiciona que la información que salga al aire muchas veces no provenga de una producción interna de la emisora sino de las fuentes establecidas como oficiales. Lo que se manifiesta en las estructuras discursivas:

-El secretario de Estado norteamericano John Kerry, dijo ayer que el bloque a Cuba debe ser eliminado porque ayudaría al pueblo de la isla caribeña, reporta Prensa Latina (1).

-EI sitio oficial CUBAMINREX informó sobre la realización de un taller en la universidad de Stanford al que asistieron académicos y empresarios estadounidenses interesados en conocer los resultados de la biotecnología cubana y su sistema de salud (2).

A su vez, la actividad ideológica estuvo enmarcada en los mecanismos que el medio orienta en función de la reproducción ideológica respondiendo al sistema social cubano. En este marco la 
propia emisora se dispone como una mediación en la defensa de la Revolución cubana y del sistema socialistas como términos máximos de su actividad. Esta mediación se manifiesta a la hora de trabajar la temática de relaciones Cuba-Estados Unidos en un discurso legitimador, de autodefensa y unificador.

\section{Construyendo la realidad: estructura y estrategia discursivas}

La máxima expresión de este nivel radicó en el uso de estrategias lingüísticas identificadas en el discurso periodístico de la emisora. Se reforzó la legitimación, la unificación, la fragmentación y la cosificación a través de estrategias de construcción simbólica que certificaron la reproducción de la ideología revolucionaria.

A nivel textual el discurso periodístico de la emisora $C M H W$ desde el punto de vista estratégico estuvo marcado por el uso de la adjetivación y la lexicalización negativa.

-oscuras e injustificadas decisiones unilaterales estadounidenses que afectan negativamente a los cubanos (3).

-el bloqueo es un acto de guerra (4).

-impacto negativo de la genocida política de cerco imperialista a Cuba (5).

De modo más específico la polarización se empleó sobre todo, en función de la estrategia de auto presentación positiva del pueblo cubano, en contraparte con la presentación negativa de la política o acciones de Estados Unidos contra Cuba:

-Se ha llegado a este momento como resultado de la heroica resistencia del pueblo cubano y su lealtad a los principios, la defensa de la independencia y la soberanía nacional en primerísimo lugar (6).

-Un pueblo que ha resistido las agresiones imperialistas durante más de medio siglo y que aspira a la construcción de un socialismo próspero y sostenible (7).

La estrategia de violación de normas y valores refuerza las evocaciones negativas de las operaciones norteamericanas:

-lo que significa el bloqueo contra Cuba en términos de una violación a los derechos humanos del pueblo cubano. Una violación de grandes proporciones a todo un proyecto de sociedad (8). Se manifiestan estrategias lingüísticas que recurren a la descripción de los acontecimientos desde una posición polarizada revelando un discurso de autodefensa: 
-continuar nuestra Revolución, que ese es el principio básico de este pueblo (9).

Se identificó en la estructura esquemática del discurso periodístico una prioridad del elemento informativo en la organización y final jerarquización de las categorías discursivas. Desde el punto de vista estructural, el discurso periodístico sobre la temática de restablecimiento de relaciones, prioriza aquellas estructuras que ponderen la objetivad y la exactitud de la información, en rezago de recursos valorativos o de opinión.

Como parte de la inmediatez que prevalece en el trabajo rutinario de la emisora, se manifestó en la estructura temática y se priorizó la actualidad como valor fundamental.

Tal vez por la inmediatez profesional. Pero yo creo que en una temática como las relaciones Cuba y Estados Unidos ya no basta con hacer información a pesar de la inmediatez. El tema es tan complicado y tan delicado que no basta reflejarlo en una información (comunicación personal, 21 de marzo de 2017).

El estilo discursivo estuvo intervenido por su condición mediática, lo que dio lugar a una frecuente impersonalidad. Las estructuras retóricas permitieron reforzar la información e imprimirle mayor precisión y exactitud al discurso, incorporando recursos lingüísticos acordes con ese objetivo como el uso de cifras:

-Alrededor de 2000 estudiantes de tres centros preuniversitarios de Santa Clara: Mariano Clemente Prado, Capitán Roberto Rodríguez y Osvaldo Herrera se reunieron en el parque Vidal para denunciar los nuevos planes subversivos de Estados Unidos contra la juventud cubana (10).

-El bloqueo es el principal obstáculo al desarrollo de Cuba como lo demuestran los perjuicios que ha provocado a nuestro país los cuales superan los 121000 millones de dólares (11).

\section{El lenguaje radiofónico}

El discurso periodístico de la emisora CMHW sobre las relaciones Cuba-Estados Unidos, acude a la expresiva del lenguaje radial para reforzar las prácticas comunicativas y sociales. El género informativo fue el de mayor presencia, mediado directamente por el factor individual y los mecanismos organizacionales, ya que de ahí emerge la convocatoria de emplear ciertos formatos para desarrollar la noticia. Se revela el interés por el enunciado de los acontecimientos, sin reparar en la valoración o la interpretación. Según las entrevistas: "Es un 
tema muy complicado en que una opinión conlleva mucho riesgo e indudablemente es más fácil hacer un género informativo, buscar una información, una entrevista, un reporte, que involucrarse con un comentario" (comunicación personal, 21 de marzo de 2017).

Otro de los formatos identificados fueron las cuñas radiales. Este recurso manifestó un poco respaldo estratégico mediado por un trabajo rutinario que responde a eventualidades. "Cada año se actualiza según las políticas del Partido. Antes eran muy frontales contra Estados Unidos, ahora son diferentes. Eso tiene que ver por dónde se mueva la política del país" (comunicación personal, 5 de mayo de 2017).

Igualmente los componentes individual y de rutinas intervienen en la implicación de los recursos del lenguaje radiofónico a la hora de trabajar la temática de relaciones Cuba Estados Unidos. Estas condicionantes traen como resultado que se suprima, el empleo de tales recursos por la premura que exige el trabajo periodístico en la emisora o por una tendencia al facilismo.

La música es el elemento con mayor presencia, desempeñando varias funciones en torno a la articulación del discurso. Los recursos menos empleados fueron el sonido y de manera inexistente el silencio. Ello demuestra la escasa explotación del lenguaje de la radio y de su valor expresivo.

La palabra mostró un equilibrado balance de voces masculinas y femeninas, tanto de locutores como de reporteros. En aquellos trabajos cuya oficialidad requería una presentación de mayor formalidad, estuvo revestida de un tono sobrio. En los reportes donde el carácter de denuncia o de oposición se enfatizaba, el tono era rotundo, vivaz, destacando cualidades como la energía y la firmeza. En las notas informativas se revelaron tonos parejos, revelando una dinámica más lineal. En los formatos donde el recurso de la opinión primaba, la naturalidad se presentó a través de un tono más coloquial, conversacional. El tono se caracterizó por ir desde escalas más vivaces, hasta las más uniformes en función de los géneros y formatos periodísticos.

\section{Conclusiones}

El discurso periodístico de la emisora CMHW sobre la temática de relaciones entre Cuba y Estados Unidos se caracteriza por ser informativo, no prima la opinión, el análisis, la valoración. Esto está condicionado por un estado de recelo, autocensura o temor a implicarse con un análisis o una opinión, que se imprime en la manera de trabajar el tema desde un discurso periodístico reservado, cauto. Se enfatiza una posición polarizada destacando la historia de 
luchas por la independencia cubana y el pasado de desencuentros y diferencias que han definido los vínculos entre ambos países.

Los medios de comunicación emergen como importantes exponentes o mediadores del acontecer políticos, asumiendo un papel activo. Como expresara Graziella Pogolotti, Cuba necesita de un periodismo que se aleje de la mera reproducción de noticias divulgadas por otros medios, que lejos de silenciar lo acontecido se vuelque hacia el análisis, la reflexión y la crítica (2017).

Las investigaciones con este corte son vitales si se quiere analizar a lo interno los procesos que median la producción radiofónica y cómo esta afecta el producto final, en qué orden es mediado ese mensaje.

El análisis desarrollado durante el estudio se inmiscuyó en el acontecer de una emisora provincial y su importancia como exponentes del patrimonio histórico, social, político y cultural de la localidad. A un nivel más cercano las emisoras locales o provinciales cubanas constituyen un importante exponente en la recreación de la realidad provincial y por ende no es factible alejar su contexto de actuación de una realidad mayor que es la nacional. La temática del restablecimiento de relaciones diplomáticas entre Estados Unidos y Cuba es un tema que compete a todo el sistema mediático de Cuba, incluyendo a las emisoras provinciales que trabajan a nivel de base, de comunidad. Entender las complejidades que tiene lugar en sus procesos productivos influye en cuánto la radio provincial defiende su sostenimiento hacia nuevas plataformas de debate y reflexiones críticas.

El emisor se presenta como principal protagonista de un discurso radiofónico que explore y divulgue el acontecer de la provincia desde cualquier arista. Para ellos es vital describir cómo desde las rutinas de producción, se recrea la realidad provincial desde las complejidades que entrañan el proceso y su relación con la identidad, la cultural, la política, etcétera.

La gran diversidad de factores que intervienen en la actividad cultural de los medios, permiten defender la hipótesis de que el proceso de comunicación de masas es complejo y está transversalizado por factores mediadores derivados de la complejidad comunicativa de los aparatos productivos.

Los contextos actuales demanda de las emisoras provinciales un distanciamiento de dinámicas meramente informativa, alejada de la crítica y de las verdaderas necesidades de las audiencias, saturadas de información y ávidas de un periodismo investigativo, de análisis profundos, ilustrativo, educativo, acorte a los nuevos retos que impone el restablecimiento de relaciones diplomáticas entre dos países distanciados por más de cincuenta años. 


\section{Notas}

(1) CMHW Nro. 000012 del 6 de octubre 2015; duración: 00:01:08.

(2) CMHW Nro. 000554 del 16 de diciembre 2016; duración: 00:01:03.

(3) CMHW Nro. 000300 del 10 de septiembre de 2016; duración: 00:00:47.

(4) CMHW Nro. 000017 del 12 de octubre de 2015; duración: 00:04:28.

(5) CMHW Nro. 000294 del 6 de septiembre de 2016; duración: 00:01:15.

(6) CMHW Nro. 000138 del 9 de marzo de 2016; duración: 00:19:24.

(7) CMHW Nro. 000151 del 21 de marzo de 2016; duración: 00:02:48.

(8) CMHW Nro. 000028 del 22 de octubre de 2015; duración: 00:03:25.

(9) CMHW Nro. 000400 del 27 de octubre 2016; duración: 00:02:37.

(10) CMHW Nro. 000338 del 30 de septiembre 2016; duración: 00:03:09.

(11) CMHW Nro. 000150 del 21 de marzo 2016; duración: 00:00:47.

\section{Bibliografía}

Amado, A. (2013). Manual de marketing y comunicación política. De la comunicación de campaña a la comunicación de ciudadanos. Ciudad Autónoma de Buenos Aires: Konrad Adenauer Stiftung.

Badía, A. T. (2010). Bases teórico-metodológicas para el análisis del discurso radiofónico como fuente de reproducción ideológica. La Voz de América: un estudio de caso (2006-2009) (Tesis de doctorado). Universidad de la Habana. Cuba.

Badía, S. T. y Soler, Y. (2016). Bases teórico-metodológicas para el análisis crítico del discurso periodístico impreso en periodos de campañas políticas. Su aplicación al estudio de la prensa venezolana. Razón y Palabra. Recuperado de www.revistarazonypalabra.org/index.php/ryp/article/download/876/925

Canel, M. (2006). Comunicación política, una guía para su estudio y práctica. Madrid: Tecnos.

Di Palma, G. (2014). El rol de los medios de comunicación en el sistema político. Relación de poder y producción periodística de la actualidad. Universidad Nacional de Córdoba: Centro de Estudios Avanzados.

Domínguez, R. (2015). Cuba y Estados Unidos: Del unilateralismo al bilateralismo formal. ¿El fin de una época? Recuperado de www.contextualizacioneslatinoamericanas.com.mx.

Domínguez, M.; Rego, I. y Castilla, C. (2014). Socialización de adolescentes y jóvenes. Resto y oportunidades para la sociedad cubana actual. La Habana: Ciencias Sociales. 
Exeni, J. L. (2005). Mediamorfosis: Comunicación Política e ingobernabilidad en democracia. La Paz, Bolivia: Plural: Ediciones FADO.

Gámez, N. (2007). El paradigma de las mediaciones: críticas y perspectivas. Recuperado de https://revistas.ucm.es/index.php/MESO/article/viewFile/Meso0707110195A/21456

Kaplún, M. (2009). Producción de programas de radio: el guión, la realización. La Habana: Félix Varela.

López, J. I. (2005). Manual urgente para radialistas apasionados. La Habana: Pablo de la Torriente.

López, G. (2017). Comunicación política y discursos sobre el poder. Recuperado de https://recyt.fecyt.es/index.php/EPI/article/viewFile/epi.2017.jul.01/36250

Machado, D. L. (2006). Introducción al análisis ideológico del contenido del discurso. La Habana: Pablo de la Torriente.

Machado, D. L. (2016). Democracia, medios de comunicación y realidades. Recuperado de http://www.cubadebate.cu/opinion/2016/08/18/democracia-medios-de-comunicacion-yrealidades/\#.WQCi0t223IU

Mazzoleni, G. (2010). La comunicación política. Madrid: Alianza Editorial.

Montero, M. D. (1989). El discurso periodístico político en la creación de estructuras públicas de significatividades. Recuperado de http://www.raco.cat/index.php/analisi/article/viewFile/41080/89082

Dell'Oro, J. (2013). Manual de marketing y comunicación política. Contexto de la Comunicación Política actual. Ciudad Autónoma de Buenos Aires: Konrad Adenauer Stiftung.

Pafundi, L. (2015). Artística e identidad radial. Programa federal de radios socioeducativas. Recuperado de http://radioies.infd.edu.ar/wp-content/uploads/2015/07/módulocapacitación-radios-ies-artísticaeidentidadradial.pdf

Parra, A. V. y Domínguez, M. (2009). Los medios de comunicación desde la perspectiva del delincuente. Revista de Ciencias Humanas y Sociales (online), 20(44), 28-54. Recuperado de http://www.scielo.org.ve/scielo.php?sci_attext\&pid=s1012$15872004000200003 \&$ lng=es\&nrm=iso >issn1012-1587

Pérez, J. (2017). Discurso periodístico y acción política. Análisis de caso, el diario Público. (Tesis doctoral). Universidad CEU Cardenal Herrera, Valencia.

Perona, J. J. (2006). El lenguaje radiofónico: introducción. Universitat Autónoma de Barcelona. Recuperado de http://www.clonica.net/usuario/img_usuario/publiradio.net/Des_Aula/271.pdf 
Pogolotti, G. (11 de marzo de 2017). El nuevo periodismo. Juventud Rebelde. Recuperado de http://www.juventudrebelde.cu/opinion/2017-03-11/el-nuevo-periodismo

Retegui, L. (2017). La construcción de la noticia desde el lugar del emisor. Una revisión del Newsmaking. Recuperado de http://www.scielo.org.mx/pdf/rmop/n23/2448-4911-rmop23-00103.pdf

Rodríguez, A. S. (2016). La evolución de la radio y la influencia de las nuevas tecnologías en la comunicación entre locutores y oyentes (Tesis de grado). Facultad de Humanidades, Universidad Rafael Landívar, Guatemala.

Santillán, J. R. (2012). Comunicación y representación política. Razón y Palabra. Recuperado de: http://www.razonypalabra.org.mx/N/N75/varia_75/01V75.pdf

Shoemaker, P. y Reese, S. (1996). Mediating the message: Theories of influences on mass media content. USA: Longman.

Thompson, J. B. (1999). Ideología y cultura moderna: Teoría crítica en la era de la comunicación de masas. México, Universidad Autónoma de Xochimilco.

Unión de Periodistas de Cuba (2017). Entre Colegas "Relaciones Cuba-Estados Unidos: hacia una cobertura de prensa diferente". Recuperado de http://www.cubaperiodistas.cu/index.php/2015/12/entre-colegas-relaciones-cuba-ee-uuhacia-una-cobertura-de-prensa-diferente/

Van Dijk, T. (s.f.). ¿Un estudio lingüístico de la ideología? Chile: Ediciones universitarias de la Universidad Católica de Valparaíso.

Van Dijk, T. (2003). El discurso como estructura y proceso. Estudios sobre el discurso I: Una introducción multidisciplinaria. España: Gedisa.

Velázquez, G. (2011). El lenguaje radial. Recuperado de http://periodismoradiofonico.wordpress.com/2010/03/el-lenguaje-radial-sesión-01utp.pdf

Wolton, D. (2010). La comunicación política: construcción de un modelo. Recuperado de http://www.altillo.com/examenes/uces/publicidad/comupolitica/comupolitica2010reswolt on.asp 